Psychopharmacologia (Berl.) 24, 384-396 (1972)

(C) by Springer-Verlag 1972

\title{
Neurochemical Correlates of the Waltzing-Shaker Syndrome in the Varitint-Waddler Mouse
}

\author{
A. R. Cools
}

Department of Pharmacology, University of Nijmegen, The Netherlands

Received September 8, 1971; Final Version November 4, 1971 
Abstract. In the order to examine activity of the dopamine system in the Varitint-waddler ( $V a)$ mouse, behavioral effects of haloperidol and dexamphetamine on waltzing $V a$, non-waltzing $V a$ and non-mutant mice were investigated. The dopamine system of these mice was studied by macro-autoradiography with ${ }^{14} \mathrm{C}$ dihydroxyphenylalanine. High doses $(5.0-10.0 \mu \mathrm{mol} / \mathrm{kg})$ of haloperidol weresimilarly effective in both mutant and non-mutant mice: they induced a highly characteristic cataleptic effect in all types of mice. Low doses $(0.10-3.16 \mu \mathrm{mol} / \mathrm{kg})$ were signifcantly less effective in the waltzing $V a$ mice: they induced a marked shift from a small increase of the sitting frequency in the waltzing mice to a large increase of this measure in the non-mutant mice. Several behavioral measures of the untreated waltzing mice mimicked those of control mice treated with amphetamine. Amphetamine reversed original strain differences and depressed several stereotyped $\nabla a$ activities. The autoradiograms of the waltzing $\nabla a$ mice, which showed a marked labelling of the Harderian gland, differed significantly from those of the nonwaltzing $V a$ mice and controls, which showed no labelling of this gland. It is suggested that a hyperactive dopaminergic mechanism is involved in the waltzingshaker syndrome of the Varitint-waddler.

Key words: Waltzing-Shaker Syndrome - Amphetamine - Haloperidol - Mice.

\section{Introduction}

In the Varitint-waddler mouse the $V a$ allele leads to a syndrome of circling, head-tossing, hyperactivity, extrapyramidal-like symptoms and deafness. These choreiform disturbances etc. are combined with a piebald spotted pattern, in which the pigment areas are reduced to nonfading spots on a fading background (Cloudman and Bunker, 1945; Cools, in press; Deol, 1954).

A hypothesis has been put forward that a striatal disorder based upon a disturbance of the dopamine-metabohism is involved in the waltzingshaker syndrome of these mutants (Cools, in press). The striatal system fulfills an important function with respect to the integration and coordination of motor activity; $V a$ disorders such as hyperactivity, disorientation, rotational behavior and presence of abnormal postures and locomotion point to a possible involvement of this system. In addition, it has been suggested by Deol (1954) that the shaking movements of the 
head may be analogous to Huntington's chorea in man, in which similar. head movements are held to be due to the involvement of the striatal system. Of importance in this context is the essential significance of dopamine (DA) for the function of the striatal system (Bloom et al., 1965; Connor, 1968; Cools and van Rossum, 1970; Cools, 1971; Herz and Zieglgänsberger, 1966; Hornykiewicz, 1966; York, 1967).

In order to examine the above-mentioned hypothesis, behavioral effects of intraperitoneally injected compounds, which interfere with DA in the Corpus striatum, were measured. It has been shown that the DA activity of the striatal system is sensitive to specific blocking and stimulating agents. Investigations on the mechanism of action of the neuroleptic drugs of the butyrophenone-group have shown that they are particularly effective in blocking the DA activity of the Corpus striatum (Cools, 1971; Costall and Olley, 1971; Florio and Longo, 1971; Fog, $1967 \mathrm{~b}$; Fog et al., 1968; Fog et al., 1970; Randrup and Munkvad, 1968). Investigations on the mechanism of dexamphetamine-like substances have shown that their central action is mediated by direct and indirect $\mathrm{DA}$ receptor stimulaton at the level of the nigrostriatal system.(Cools, 1971; Fog et al., 1967a; Fuxe and Ungerstedt, 1970; McKenzie and Szerb, 1968; Randrup and Mundvad, 1970). Haloperidol, a neuroleptic drug of the butyrophenonegroup, and dexamphetamine were therefore used as experimental tools in order to examine the striatal system of the Varitint-waddler. In order to examine histochemical disturbances of the dopamine system, a study was made by means of macro-autoradiography.

The evidence presented in this paper strongly supports the hypothesis that a disorder of the dopamine system is involved in the waltzingshaker syndrome of the Varitint-waddler.

\section{Experimental Animals}

Male mice ranging in weight from $18-26 \mathrm{~g}$, sixty to hundred and twenty days of age, were used routinely in this study. The animals came from the $F_{1}$ of two stocks, one heterozygous for $V a$ and the other homozygous for dilute $(d d): \mathrm{C} 57 \mathrm{BL} / 6 \mathrm{~J}$. The details of the segregation of the gene $V a$ are described by Cools (in press). Each $\mathbf{F}_{1}$ littersize was reduced to $7-8$ animals in order to ensure some uniformity in nutrition and growth rate. Littermates were kept together in large perspex cages $(32 \times 21 \times 16 \mathrm{~cm})$ until the 30 th postnatal day; from this day on each animal was isolated in a small perspex cage $(13 \times 21 \times 16 \mathrm{~cm})$ with beddings of peat dust and metal covers. Since it was noted in a previous study that one group of the $V a$, which had no spots, did not turn at all (Cools, in press) waltzing (w Va/+) and non-waltzing (nw $V a /+)$ mutants were tested separately; non-mutant littermates $(+/+)$ were used as controls. 
The temperature $\left(22^{\circ} \mathrm{C}\right)$, day/night periodicity and light intensity were standardized. Food and water were supplied ad libitum; during the experiments only food was available.

\section{Miethods}

For each experiment three groups, each including 12 animals, were tested: A. wild-type mice $(+/+)$; B. non-waltzing mutants $(\mathrm{nw} V a /+)$; C. waltzing mutants (w $\mathrm{Va} /+$ ). In order to test the effect of haloperidol, frequency counts of sitting displayed by the mice in their own homecages were made every $30 \mathrm{sec}$ according to the time-sample method for a period of $30 \mathrm{~min}$; each period included six successive sessions of $5 \mathrm{~min}$. Twelve min prior to testing the animals received the haloperidol injection. In order to test the effects of dexamphetamine frequency counts of ten behavioral components displayed by the mice in their own home-cages were made every $30 \mathrm{sec}$ for a period of $30 \mathrm{~min}$ : sitting, cleaning, eating, sniffing at the ground, reconnoitering, digging, circling, tail-raising, headtossing and "miscellaneous"; miscellaneous comprised jumping, waddling, forward and backward locomotion. For a description of the first mentioned items reference is made to Abeelen (1966); postures and acts such as leaning against a wall, climbing wire mesh etc. were not registered in view of the low scores obtained in preliminary experiments. Six min prior to testing the animals were injected. Haloperidol and dexamphetamine-sulphate were administered intraperitoneally in $0.9 \%$ saline. All solutions of chemical agents were prepared freshly prior to injection $(0.1 \mathrm{ml} / \mathrm{kg})$. In an initial test for each substance mice received a single injection of the agents at 5 geometrically spaced concentration levels ranging from 1.0 to $20.0 \mu \mathrm{mol} / \mathrm{kg}$ in order to determine the effective dosage. Since haloperidol induced continuous sitting at the concentration level of $5 \mu \mathrm{mol} / \mathrm{kg}$, supplementary experiments were conducted at more closely spaced dosage increments. As haloperidol induced qualitatively similar, but quantitatively different effects in both mutants and nonmutants, five different concentrations (see Fig. 1) were chosen for the definite test. Dexamphetamine at a concentration of $10 \mu \mathrm{mol} / \mathrm{kg}$ induced clearly observable changes in the behavior of both $\mathrm{Va} /+$ and $+1+$ mice and this dose was chosen for the dexamphetamine test.

In order to study the aminergic system, the autoradiographic technique of Ullberg (1954) was used. Male mice, $+/+, \mathrm{nw} \mathrm{Va} /+$ and $\mathrm{w} \mathrm{Va} /+$ ranging in weight from $18-22 \mathrm{~g}$, sixty days of age, were given $20 \mathrm{mg}$ $(200 \mu \mathrm{C}) / \mathrm{kg}{ }^{14} \mathrm{C}$-dihydroxyphenylalanine (DOPA) intraperitoneally; twenty min prior to the DOPA injection Ro-4-4602 ( $\mathbf{N}^{\mathbf{1}}$-DL-seryl-N ${ }^{2}$. (2,3,4-trihydroxybenzyl)-hydrazine was given in order to block extracerebral decarboxylase without inhibition of cerebral decarboxylase (Bartholini et al., 1967; Constantinides et al., 1968). The mice received 
$0.1 \mathrm{ml} / \mathrm{kg}$ of saline solution, in which the compounds were dissolved. After a survival period of $\mathbf{2} \mathbf{h}$, the animals were decapitated and frozen according to the mentioned method. Frontal sections of the head and sagittal sections of the body, $20 \mu$ thick, were made; sections were stuck to Scotch Tape, freeze-dried and pressed on to Structurix (Gevaert) D $7 \mathrm{X}$-ray films and exposed for 20 to 30 days at $-12^{\circ} \mathrm{C}$.

\section{Results}

In general, haloperidol at dose levels higher than $5 \mu \mathrm{mol} / \mathrm{kg}$ induced catalepsy in all types of mice. However, lower concentrations resulted only in a reduction of normal activities : noabnormal postures or movement were elicited. Since the reduction of the behavioral activities started at about $25 \mathrm{~min}$ after the injection, only the data of the third session (22 to 27 min after the injection) were analyzed. The values found for the responses of the three types of mice on different doses of haloperidol were arranged in the cumulative concentration curves of Fig. 1, in which the percentages of the maximum scores of sitting frequency (S/Sm) of 12 animals were plotted against the logarithmic dose concentration. Differences in responses on the same dose of the different types were evaluated nonparametrically by means of the two-tailed Wilcoxon test (Siegel, 1956). The values obtained for $+/+$ and nw $\mathrm{Va} /+$ mice showed that the effects of the same dose of haloperidol in both groups were very similar, although the significant difference $(p \leqslant 0.05)$ at the dose $0.10 \mu \mathrm{mol} / \mathrm{kg}$ suggested that haloperidol was somewhat less effective in the nw $\mathrm{Va} /+$ (Table 1). However, significant differences were found for the w $V a /+$ mice on all ocasions (Table 1). Moreover, calculations of differences in responses of successive dosage increments gave significant differences ( $p \leqslant 0.05$ in the two-tailed Mann-Whitney test) for the nw $\mathrm{Va} /+$ at dosage steps $0.316-0.750,0.750-2.32$ and $2.32-3.16 \mu \mathrm{mol} / \mathrm{kg}$, but only significant differences for the $+1+$ mice and the nw $\mathrm{Va} /+$ miee at the dosage steps $0.00-0.10$ and $0.10-0.316 \mu \mathrm{mol} / \mathrm{kg}$. Thus, the haloperidol effect was significantly less effective in the $\mathrm{w} \mathrm{Va} /+$.

All data of the saline-amphetamine test are arranged in Tables 2-4. Differences in responses of the $+/+$ and $V a /+$ mice on the two drugs were evaluated by means of the nonparametric two-tailed MannWhitney test (Siegel, 1956), while differences in responses to the same drug of the different types of mice were evaluated by means of the twotailed Wilcoxon test or the Fisher exact test (Siegel, 1956). As shown in Table 2 , the scores of several behavioral activities in the $+1+$ mice differed originally from those of the mutants: for instance, $+1+$ scored significantly lower than the nw $\mathrm{Va} /+$ for sitting, but significantly higher for cleaning, sniffing and reconnoitering; in contrast, $+/+$ scored significantly lower than $\mathrm{w} \mathrm{Va} /+$ for reconnoitering, but significantly higher 


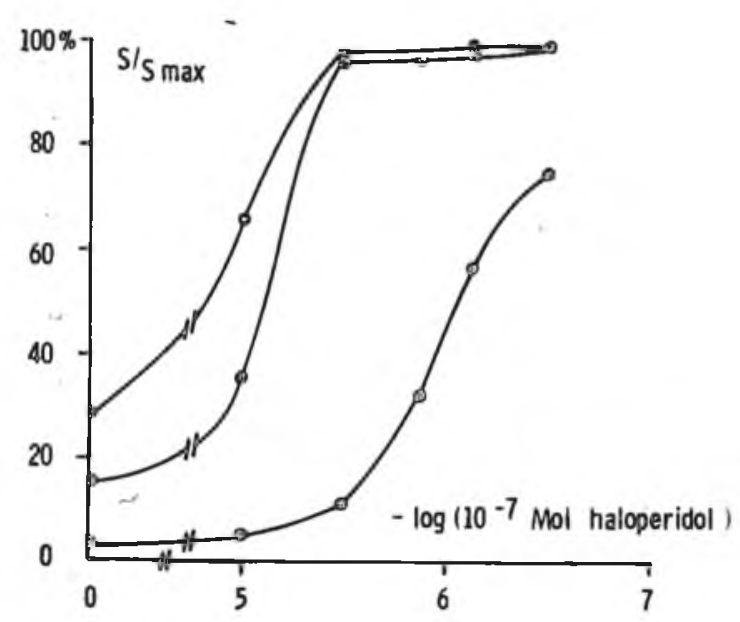

Fig. 1. Sitting-scores of $+/+(0)$, non-waltzing $V a /+(\odot)$, and waltzing $V a /+(0)$, following i.p. injections of haloperidol. $S / S$ max is the percentage of the maximumscore of sitting-frequency of 12 mice during the third session

Table 1. Differences in responses to increasing doses of haloperidol in wild-type $(+/+)$, non-waltzing ( $n w V a /+)$ and waltzing mice $(w V a /+)$

\begin{tabular}{llll}
\hline $\begin{array}{l}\text { Haloperidol } \\
(\mu \mathrm{mol} / \mathrm{kg})\end{array}$ & $+/+\mathrm{vs} \mathrm{nw} \mathrm{Va} /+$ & $+/+\mathrm{vsw} \mathrm{Va}+$ & $\mathrm{nwVa} /+\mathrm{vs} \mathrm{W} \mathrm{Va} /+$ \\
\hline 0.00 & $\mathrm{~ns}$ & $*$ & $*$ \\
0.10 & $*$ & $*$ & $*$ \\
0.316 & $\mathrm{~ns}$ & $*$ & $*$ \\
0.750 & $\mathrm{~ns}$ & $*$ & $*$ \\
$\mathbf{2 . 3 2}$ & $\mathrm{ns}$ & $*$ & $*$ \\
\hline 3.16 & $\mathrm{~ns}$ & $*$ & \\
\hline
\end{tabular}

* significant at $p \leqslant 0.05$ (Wilcoxon test).

for cleaning, sitting and sniffiing. Thus, marked differences were observed not only between the non-mutant and mutant mice, but also between the nw $V a /+$ and w $V a /+$ mice. In fact, the pleiotropic effects of the $V a$ allele on behavioral activities were drastic and appeared to influence the whole behavior pattern.

As shown in Tables 2-4 the effects of amphetamine were characteristic for each group of mice. For instance, the abnormally low sitting scores of the $\mathrm{w} \mathrm{Va} /+$ were significantly increased and appeared to be similar to the scores of the untreated $+1+$ mice, while the sitting scores of the $+1+$ mice were significantly lowered and appeared to be similar to the scores of the untreated $\mathrm{w} V \mathrm{~V} / \mathrm{+}$ animals; in contrast, the very high reconnoiter- 


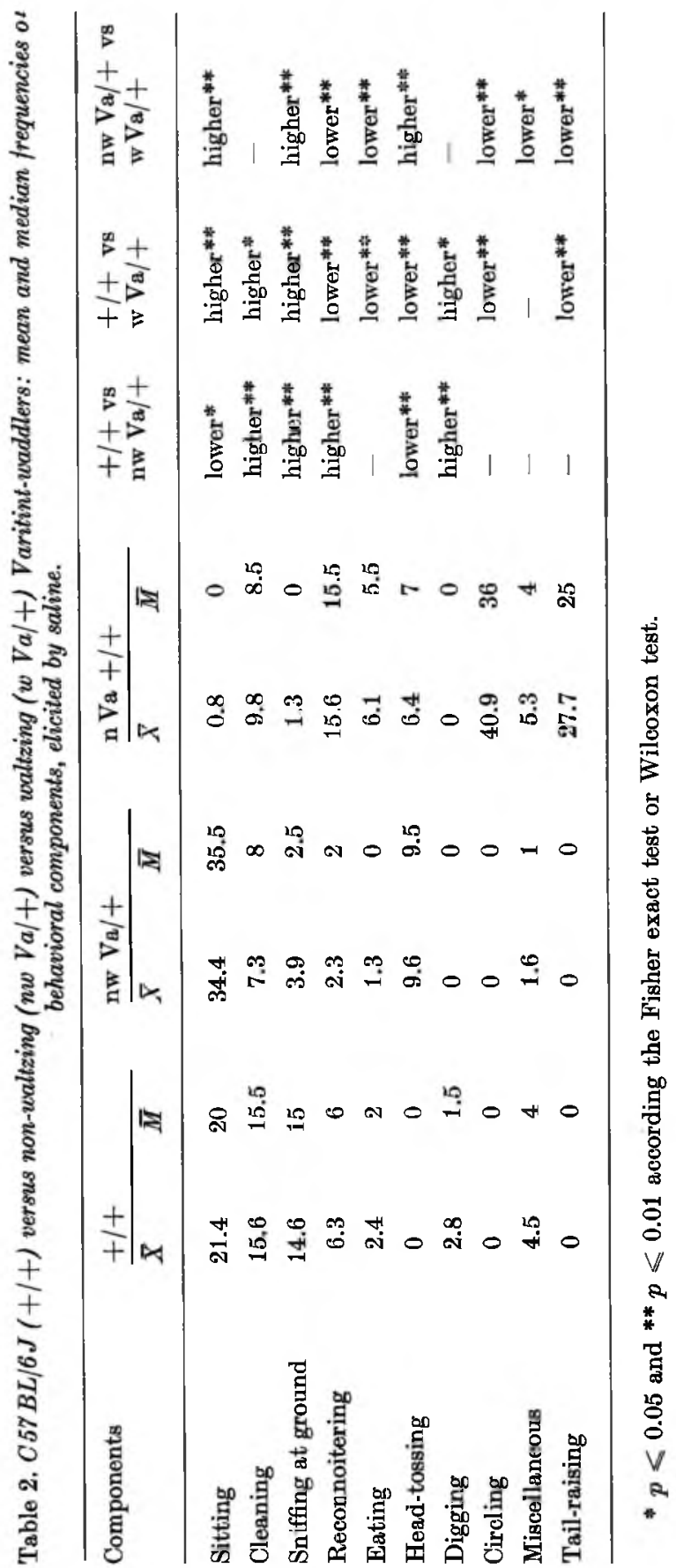


A. R. Cools :

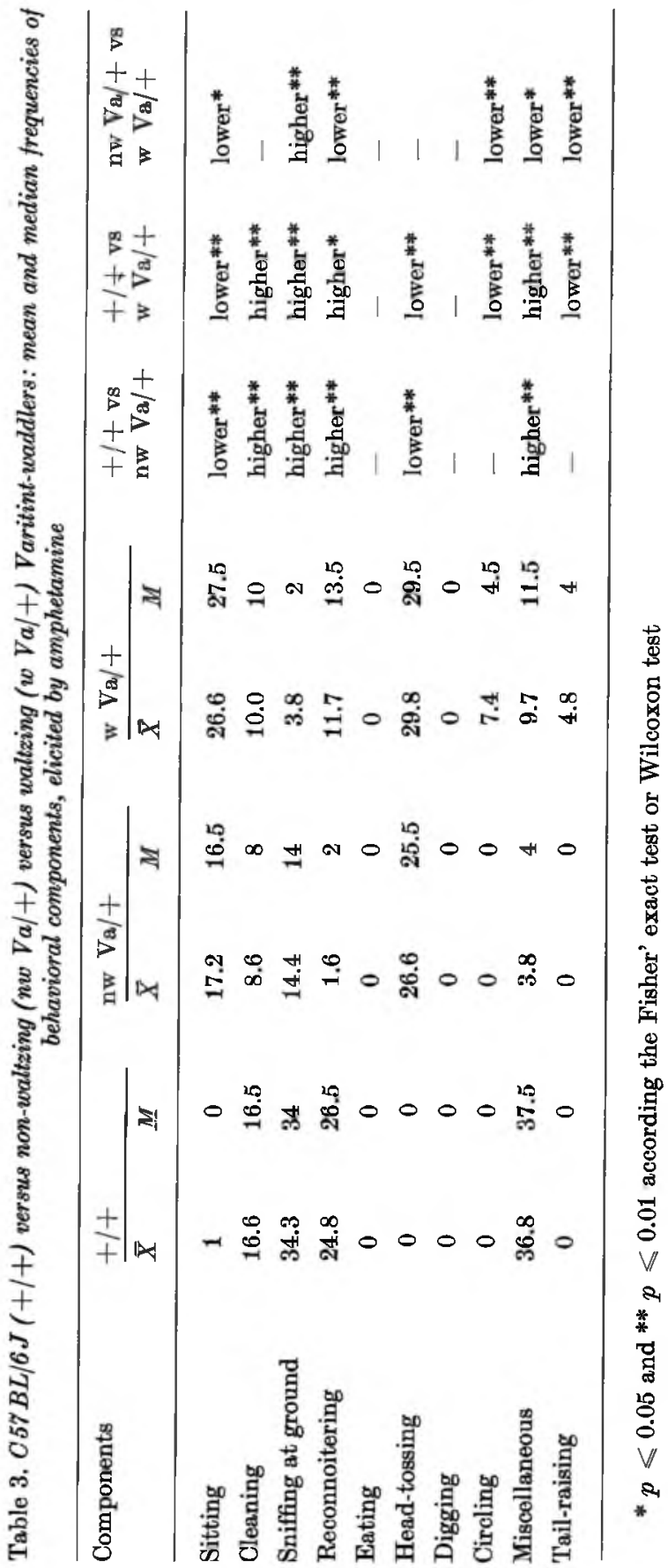


Table 4. C57BL/6J $(+/+)$, non-waltzing (nw Va/+) and waltzing (w Va/+) Varitint-waddlers: statistical differences between the saline and amphetamine effects upon behavioral components

\begin{tabular}{llll}
\hline Components & $+1+$ & $\mathrm{nw} \mathrm{Va} /+$ & $\mathrm{w} \mathrm{Va} /+$ \\
\hline Sitting & decrease & decrease** & increase** \\
Cleaning & - & - & - \\
Sniffing at ground & increase** & increase** & increase* \\
Reconnoitering & increase** & - & decrease* \\
Eating & decrease* & - & decrease** \\
Head-tossing & - & increase** & increase** \\
Digging & decrease* & - & - \\
Circling & - & - & decrease** \\
Miscellaneous & increase** & increase* & increase** \\
Tail-raising & - & - & decrease** \\
\hline
\end{tabular}

$* p \leqslant 0.05$ and $* * p \leqslant 0.01$ according the Mann-Whitney test.

ing scores of the $\mathrm{w} V a /+$ mice were reduced, while those of the $+1+$ mice were just significantly increased. Apart from these opposite effects, the effects upon sniffing, cleaning and miscellaneous were similar in all types of mice: amphetamine had no influence upon the cleaning scores and increased the scores of sniffing and miscellaneous, although in both cases a marked shift was observed from a large increase of these activities in the $+1+$ mice to a very small increase in the $w \mathrm{Va} /+$. From the stereotyped activities of the $\mathrm{w} \mathrm{Va} /+$ circling and tail raising were decreased, while head tossing was increased. Digging activity was totally absent in both untreated and treated $V a /+$ mice and although originally present in the $+1+$ mice, was suppressed by the amphetamine injection. A marked decrease of the eating scores in the $+\mid+$ and $\mathrm{w} \mathrm{Va} /+$ mice was induced by amphetamine. Circling and tail-raising were not seen in $+1+$ and nw $\mathrm{Va} /+$ mice and the head-tossing scores of the nw $\mathrm{Va} /+$ mice had the same tendency as those of the $\mathrm{w} V a /+$ mice: a significant increase after the amphetamine injection.

Finally, examinations of the body autoradiograms revealed that the labelled tissues were essentially similar for the three types of mice. However, examinations of the head sections resulted in the appearance of a significant difference between the $\mathrm{w} V \mathrm{Va}+$ mice and the other phenotypes as shown in Fig. 2: the Harderian gland of the w $V a /+$ mice was strongly labelled, while the glands of the other ones were unlabelled.

\section{Diseussion}

Neuroleptic drugs like haloperidol have been shown to elicit a lighly characteristic cataleptic effect in several species by blocking the 


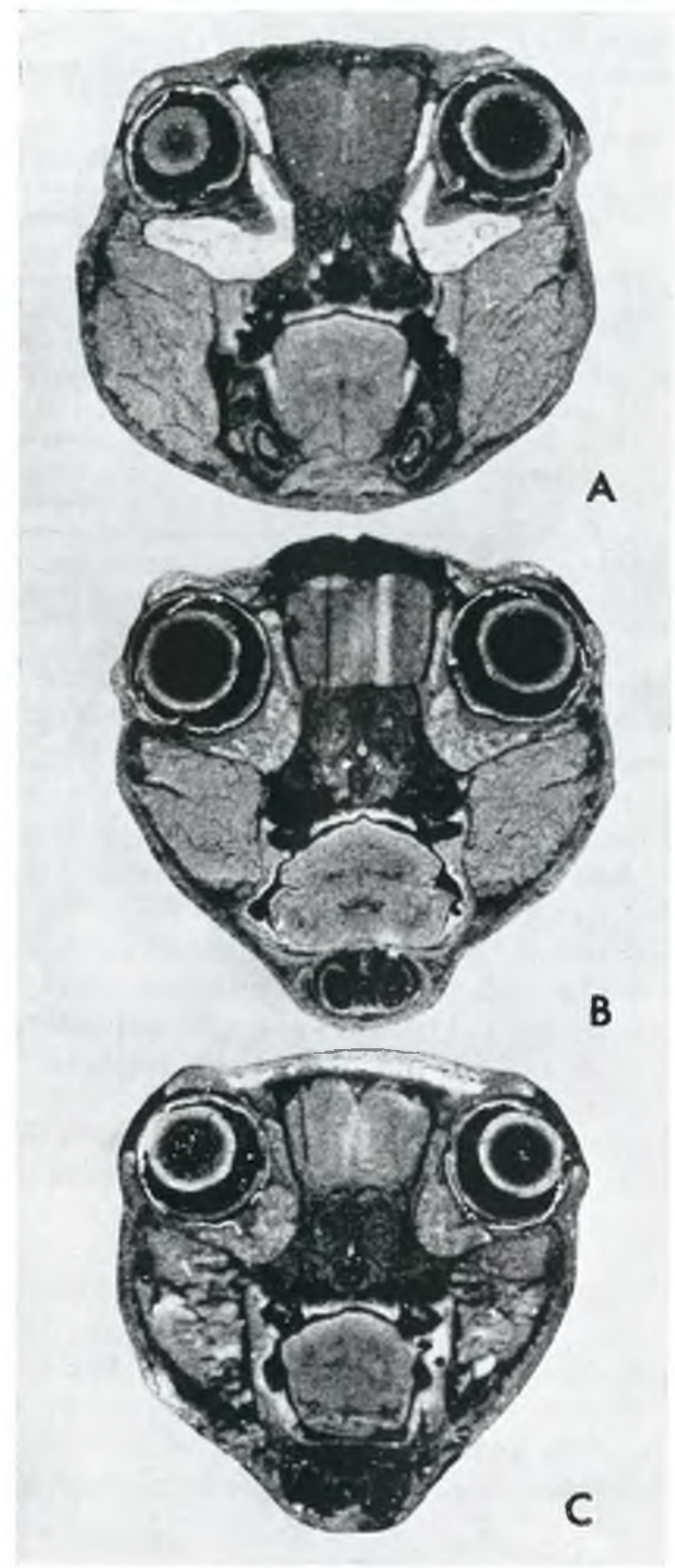

Fig.2A-C. $\left({ }^{14} \mathrm{C}\right)$ DOPA-autoradiograms of waltzing (A); non-waltzing (B); Varitintwaddlers and $\mathrm{C} 57 \mathrm{BL} / 6 \mathrm{~J}(\mathrm{C})$ : frontal sections of the mouse head. Note the labelled Harderian gland in (A) 
dopaminergic activity of the striatal system (Costall and Olley, 1971); Florio and Longo, 1971; Fog, 1967b; Fog et al., 1968; Fog et al., 1970). The finding that high concentrations of haloperidol induced catalepsy in the Varitint-waddler indicates that the striatal system of the $\mathrm{Va} /+$ is sensitive to the blocking action of haloperidol; in fact, the cataleptic effect points to a functional integrity of the striatal system, since lesions of this system abolishes the effect (Fog et al., 1970). The experiments with low doses of haloperidol showed that reduction of nearly all behavioral activities, except for sitting, occurred in all types of mice. However the results of Fig. 1 showed a marked shift from a more rapid and large increase of sitting frequency in the $+1+$ mice to a slower and intermediate increase of sitting frequency in the $\mathrm{w} V \mathrm{Va} / \mathrm{+}$. It would, therefore, seem that the blocking activity of haloperidol in the striatal system is reduced. Since high doses of haloperidol induced essentially similar effects in the non-mutants, the differences in the dose-dependent effect of haloperidol may be most simply explained by assigning a dopaminergic hyperactivity to the striatal system of the Varitints. This is further supported by the results of the dexamphetamine tests.

It has been shown that amphetamine gives rise in several species to characteristic stereotyped behavior by activating the dopaminergic mechanism of the nigrostriatal system (Fog et al., 1967a; Fog, $1967 \mathrm{~b}$; Fog et al., 1970; Fuxe and Ungerstedt, 1970; Randrup and ScheelKrüger, 1966; Randrup and Munkvad, 1970). From the comparison of the hyperactive mutants with the $+1+$ mice, clear differences emerged: several characteristic activities of the untreated $V a$ did not differ from the stereotyped activities induced by amphetamine in the $+1+$ mice. For instance, amphetamine induced sitting scores in the $+1+$ mice, which were essentially similar to the scores of the untreated $\mathrm{w} \mathrm{Va} /+$ mice. In contrast, amphetamine reversed the originally low sitting scores of the untreated $V a$ to those of the untreated $+1+$ mice; in view of this data, it may be mentioned that the amphetamine effect in hyperactive children is also reversed in comparison with the drug effect in normal children (Lasagna and Epstein, 1970). The same holds for several activities as shown in Tables 3 and 4 . In addition, the high miscellaneous scores of the $+1+$ mice treated with amphetamine consisted mostly of scores of retropulsive movements; movements which were normally present in the untreated $\mathrm{w} V a /+$ mice.

From these data, it may be concluded that the behavior of the Varitintwaddler mimics in several aspects the behavior of normal mice treated with the dopamine stimulating agent, amphetamine. Furthermore, it may be concluded from the observed differences between $\mathrm{nw} V \mathrm{~V} /+$ and w $V a /+$ mice that the $V a$ genotype has an incomplete penetrance and a variable expressivity; it is noteworthy that the genotype of Huntington's 
chorea in man, which may be partially analogous to the $V a$ syndrome as mentioned in the introduction, has the same phenotypic effect with respect to its penetrance and expressivity (Dobzansky, 1958). Both the mimicking action of amphetamine and the ineffectiveness of low doses of the dopamine blocking agent haloperidol suggest that the $V a$ allele exerts its effects by an increased dopamine activity, particularly in the striatal system. In view of the suggestion that a hypersensitive-dopaminergic mechanism of the Corpus striatum is involved in Huntington's chorea (Klawan, 1970), the increase in the head-tossing scores of the Varitint-waddler, following amphetamine-injection, strengthens this assumption.

However, when examining carefully the isotopically labelled sections of the dopamine-rich areas of the brain, i.e. the Corpus striatum, no gross histochemical differences were found between $+/+$ and $\mathrm{Va} /+$ mice. Since it has been shown that inhibition of the extracerebral and brain capillary L-DOPA decarboxylase resulted in an increased penetration of L-DOPA into the brain parenchyma and enhanced the amount of DA in the dopaminergic brain areas (Constantinides et al., 1968) quantitative differences could have been masked by the DA increase induced by the Ro-4-4602 pretreatment in the brain of all mice.

In contrast, the penetration of L-DOPA or its metabolites into the Harderian gland of the waltzing Varitint-waddler supports the assumption that the $V a$ allele exerts its effects by interference with the dopamine mechanism: the Harderian gland, which may be functioning as an extraretinal photosensitive organ (Wetterberg et al., 1970) contains melanocytes, which have a melanin-synthesizing mechanism (Searle, 1968). In the melanocytes, melanin is formed through the oxidation of L-DOPA, the precursor of dopamine. The abnormal piebald spotting pattern of the fur points into the same direction, since a similar melaninsynthesizing system is involved in the determination of the pigment areas.

In addition, the correation between the localisation of the nonfading spots and the dominant direction of circling movements (Cools, in press) suggest that the pigment dis order and the dyskinesia are based upon one common mechanism of action: the dopamine synthesizing system, which has an essential significance both in the striatal nuclei and in the process of skin pigmentation. As a final remark, it is interesting to note that an inner-ear defect resembling that of the Varitint-waddler is associated with the absence of melanin in the membraneous labyrinth of the coat-color mutants, pallid and muted (Erway et al., 1966); however, the involvement of the dopamine-synthesizing mechanism in this defect awaits confirmation from other studies. 
In conclusion, our results indicate that a hyperactive dopaminergic mechanism is involved in the waltzing-shaker syndrome of the Varitintwaddler. With respect to the regularly occurring association of one or more of the triad psychosis, dyskinesia and hypopigmentation or hyperpigmentation in man (Proctor, 1971), it may be relevant to consider the Varitint-waddler as a tool for therapeutic investigations because of its potential analogy to striatal disorders in man such as schizophrenic-like psychosis, Huntington's chorea etc.

\section{References}

Abeelen, J. H. F. van: Behavioural profiles of neurological mutant mice. Genetica 37, $149-158$ (1966).

Bartholini, G., Bates, H. M., Burkhard, W. P., Pletcher, A.: Increase of cerebral catecholamines caused by 3,4-dihydroxyphenylaline after inhibition of peripheral decarboxylase. Nature (Lond.) 215, 852 (1967).

Bloom, F. E., Costa, F., Salmoiraghi, G. C. J.: Anesthesia and the responsiveness of individual neurons of the caudate nucleus of the cat to acetylcholine, epinephrine and dopamine, administered by microelectrophoresis. J. Pharmacol. exp. Ther. 150, 244 (1965).

Cloudman, A. M., Bunker, L. F., Jr.: The Varitint-waddler mouse. A dominant mutation in Mus musculus. J. Hered. 36, 259 (1945).

Connor, J. D.: Caudate unit responses to nigral stimuli: evidence for a possible nigro-striatal pathway. Science 160, 899 (1968).

Constantinides, J., Bartholini, G., Tissot, R., Pletcher, A.: Accumulation of dopamine in the parenchyma after decarboxylase inhibition in the capillaries of the brain. Experientia (Basel) 21, 130 (1968).

Cools, A. R.: The function of dopamine and its antagonism in the caudate nucleus of cats in relation to the stereotyped behaviour. Arch. int. Pharmacodyn. (in press) (1971).

- Asymmetry in fur pattern and laterality in circling behaviour in the Varitintwaddler (Va) mouse. (In press) (1971).

- Rossum, J. M. van: Caudal dopamine and stereotype behaviour of cats. Arch. int. Pharmacodyn. 187, 136 (1970).

Costall, B., Olley, J. E.: Cholinergic- and neuroleptic-induced catalepsy: modification by lesions in the caudate-putamen. Neuropharmacology 10, 297 (1971).

Deol, M. S.: The anomalies of the labyrinth of the mutants Varitint-waddler, shaker-2 and Yerker in the mouse. J. Genet. 42, 562 (1954).

Dobzankky, T.: Principles of genetics, p. 130. Eds. E. W. Sinnott, L. C. Dunn, and T. Dobzansky. Now York: Mc Graw-Hill 1958.

Erway, L., Hurley, L. S., Fraser, A.: Neurological defect: Manganese in phenocopy and prevention of a genetic abnormality of inner ear. Science 152, 1766 (1966).

Florio, V., Longo, V. G.: Neuroleptic drugs and the central dopaminergic system. Neuropharmacology 10, 45 (1971).

Fog, R.: Role of the corpus striatum in typical behavioral effects in rats, produced by both amphetamine and neuroleptic drugs. Acta pharmacol. (Kbh.) 25, suppl. 4, 50 (1967b). 
Fog, R., Randrup, A., Pakkenberg, H. : Aminergic mechanism in corpus striatum and amphetamine-induced stereotyped behaviour. Psychopharmacologia (Berl.) 11, 179 (1967 a).

- - - Neuroleptic action of quaternary chlorpromazine and related drugs injected into various brain areas in rats. Psychopharmacologia (Berl.) 12, 428 (1968).

- - - Destruction in corpus striatum and cortex in cat brains and the effects on pharmacologically-induced stereotyped aggressive and cataleptic behaviour. Psychopharmacologia (Berl.) 18, 346 (1970).

Fuxe, K., Ungerstedt, U.: Histochemical, biochemical and functional studies on cerebral monoamines neurons after acute and chronic amphetamine administration. In: Amphetamines and related compounds, p. 257. Eds. E. Costa and S. Garattini. New York: Raven Press 1970.

Herz, A., Zieglgänsberger, W.: Synaptic excitation in the corpus striatum inhibited by microelectrophoretically administered dopamine. Experientia (Basel) 22, 839 (1966).

Hornykiewicz, O.J.: Dopamine (3'-hydroxytyramine) and brain dysfunction. Pharmacol. Rev. 18, 925 (1966).

Klawan, H. L. : A pharmacologic analysis of Huntington's chorea. Europ. Neurol. 4, $148(1970)$.

Lasagna, L., Epstein, L. C.: The use of amphetamine in the treatment of hyperkinetic children. In: Amphetamines and related compounds, p. 849. Eds. E. Costa and S. Garattini. New York: Raven Press 1970.

McKenzie, G. M., Szerb, J. C.: The effect of dihydroxyphenylalanine, pheniprazine and dextroamphetamine on the in vivo release of dopamine from the caudate nucleus. J. Pharmacol. exp. Ther. 162, 32 (1968).

Proctor, P.: Psychosis, Dyskinesia and Hyperpigmentation. Lancet 1971, 1069.

Randrup, A., Munkvad, I.: Behavioural stereotypes induced by pharmacological agents. Pharmacopsychiat. 1, 18 (1968).

- - Biochemical, anatomical and psychological investigations of stereotyped behaviour induced by amphetamine. In: Amphetamines and related compounds, p. 695. Eds. E. Costa and S. Garattini. New York: Raven Press 1970.

- Scheel-Krüger, J.: Diethyldithiocarbamate and amphetamine stereotyped behaviour. J. Pharm. Pharmacol. 18, 752 (1966).

Searle, A. G.: Comparative genetics of coat colour in mammals, p. 45. London: Logos Press 1968.

Siegel, S.: Nonparametric statistics for the behavioural Sciences. New York: MeGraw Hill 1956.

Ullberg, S.: Studies on the distribution and fate of ${ }^{35} \mathrm{~S}$-labelled benzylpenicillin in the body. Acta radiol. (Stockh.) Suppl, 118, 1 (1954).

Wetterberg, L., Yuwiler, A., Ulrich, R., Geller, E., Wallace, R.: Harderian gland: influence on pineal hydroxyindol-O-methyltransferase activity in neonatal rats. Science 170, 194 (1970).

York, D. H.: The inhibitory action of dopamine on neurons of the caudate nucleus. Brain Res. 5, 263 (1967).

\author{
A. R. Cools \\ Department of Pharmacology \\ University of Nijmegen \\ Nijmegen, The Netherlands
}

